\title{
Genetic Moderation of Intervention Efficacy: Dopaminergic Genes, The Incredible Years, and Externalizing Behavior in Children
}

\author{
Rabia R. Chhangur and Joyce Weeland \\ University of Amsterdam and Utrecht University
}

\author{
Geertjan Overbeek \\ University of Amsterdam
}

\author{
Danielle van der Giessen \\ University of Amsterdam
}

\author{
Jay Belsky \\ University of California, Davis
}

\begin{abstract}
This study investigated whether children scoring higher on a polygenic plasticity index based on five dopaminergic genes (DRD4, DRD2, DAT1, MAOA, and COMT) benefited the most from the Incredible Years (IY) parent program. Data were used from a randomized controlled trial including 341 Dutch families with 4- to 8-year-old children (55.7\% boys) showing moderate to high levels of problem behavior. IY proved to be most effective in decreasing parent-reported (but not observed) externalizing behavior in boys (but not girls) carrying more rather than fewer dopaminergic plasticity alleles; this Gene $\times$ Intervention effect was most pronounced in the case of boys whose parents' manifested the most positive change in parenting in response to the intervention. These results proved robust across a variety of sampling specifications (e.g., intention to treat, ethnicity).
\end{abstract}

Elevated levels of externalizing behavior (e.g., aggression, oppositional behavior, disobedience) in the early years of life forecasts a variety of problems later in childhood (Campbell et al., 2006). Left untreated, externalizing behavior often worsens with age and tends to persist over time (Mesman, Bongers, \& Koot, 2001; Vaughn, Salas-wright, Delisi, \& Maynard, 2013), generating substantial social and economic costs to individuals and society (Raaijmakers, Posthumus, Van Hout, Van Engeland, \& Matthys, 2011; Scott, Knapp, Henderson, \& Maughan, 2001). These observations underscore the importance of early intervention to ameliorate such early emerging problems. Some of the most effective interventions in this regard are designed to increase positive parenting behavior. Such behavioral parent training programs employ parents as change agents, enabling them to deploy more positive parenting practices, thereby reducing problematic child behavior (Forehand, Lafko, Parent, \& Burt, 2014).

Not all children benefit equally from interventioninduced changes in positive parenting behavior.

This work was financially supported by The Netherlands Organization for Scientific Research (NWO: 452-10-005).

Correspondence concerning this article should be addressed to Rabia R. Chhangur, Research Institute of Child Development and Education, University of Amsterdam, PO Box 15776, 1001 NG, Amsterdam, The Netherlands. Electronic mail may be sent to r.r.chhangur@uva.nl.
Conversely, not all children who appear to be at risk for developing externalizing problems - as a result of exposure to unsupportive, negative, and harsh parenting-do so. These differential responses to, respectively, parenting support and risk raise questions about the source of such heterogeneity. For quite some time now it has been presumed that some children are more at risk because of their own characteristics of "vulnerability," be they temperamental, physiological, and/or genetic in nature. Indeed, this notion is central to the long-standing diathesis-stress model of Person $\times$ Environment interaction that has informed much research (e.g., Zuckerman, 1999). However, this "vulnerability" framework is less adequate in explaining heterogeneity in response to environmental support and enrichment.

Recently, an alternative Person $\times$ Environment framework has been advanced which explicitly addresses differential response to both risk and support. This differential susceptibility perspective stipulates that the very personal characteristics that

[Correction added on October 17, 2016, after first online publication on September 15, 2016: Some numbers in Tables 2, 3, and 4 were incorrect. These tables have been corrected.] (c) 2016 The Authors

Child Development $\odot 2016$ Society for Research in Child Development, Inc. All rights reserved. 0009-3920/2017/8803-0009

DOI: $10.1111 /$ cdev.12612 
make a child especially vulnerable to adversity may also enable him or her to benefit more so than others from support and enrichment (Belsky, Bakermans-Kranenburg, \& Van IJzendoorn, 2007; Belsky \& Pluess, 2009, 2013; Boyce \& Ellis, 2005, Ellis, Boyce, Belsky, Bakermans-Kranenburg, \& Van IJzendoorn, 2011)). In doing so, this evolutionary inspired framework implies that it will be children regarded as especially vulnerable to adversity due to their personal characteristics who would benefit the most from efforts to promote well-being, to prevent problems from developing in the first place, and to ameliorate existing problems (Belsky \& Van IJzendoorn, 2015; Van IJzendoorn \& BakermansKranenburg, 2015).

Here, we test this differential-susceptibilityderived proposition that some children are more susceptible to intervention-induced environmental change than others by focusing on their genetic makeup. Specifically, we test the hypothesis that children manifesting moderate to high levels of problem behavior and carrying more of particular variants of a set of dopaminergic genes (i.e., "plasticity alleles") will benefit more than their peers from the Incredible Years (IY) parenting intervention (Webster-Stratton, 2001b). This prediction is also based on recent research on the genetic moderation of intervention efficacy (Belsky \& Van IJzendoorn, 2015; Van IJzendoorn \& BakermansKranenburg, 2015) and evidence that dopaminergic genes moderate environmental effects in a differential-susceptibility-related, "for-better-and-for-worse" manner (Bakermans-Kranenburg \& Van IJzendoorn, 2011). Because IY seeks to change children by increasing positive parenting, including their use of praise, tangible rewords, and other positive reinforcements (e.g., Beauchaine, Webster-Stratton, \& Reid, 2005; Gardner, Hutchings, Bywater, \& Whitaker, 2010), we also predicted, following Bakermans-Kranenburg, Van IJzendoorn, Pijlman, Mesman, and Juffer (2008), that it would be children who carried the most putative plasticity alleles and whose parents evinced the most increase in positive parenting in response to the IY program who would benefit the most from the intervention.

\section{Parenting and Externalizing Behavior}

Extensive evidence indicates that parenting behavior is longitudinally associated with child behavior (e.g., Miner \& Clarke-Stewart, 2008). Negative parenting strategies in particular are related to elevated levels of externalizing behavior, including inconsistent discipline, disapproval, harshness, physical discipline, lack of positive tone, and coercion (Gershoff, 2002; Pettit \& Bates, 1989; Shaw, Keenan, \& Vondra, 1994). In contrast, positive parenting strategies that convey warmth and acceptance and provide positive consequences for desirable behavior while enhancing the parent-child relationship can prevent externalizing behavior from persisting and increasing over time (Dishion et al., 2009; Gardner, Shaw, Dishion, Burton, \& Supplee, 2007).

\section{The Incredible Years Program}

Given these observations, it is not surprising that efforts to prevent the development of severe externalizing problem behavior have targeted parenting, seeking to reduce negative while promoting positive parenting practices. IY parent training (Webster-Stratton, 2001b) is one such program designed to prevent the development of child externalizing behavior problems or to ameliorate early emerging problems and is therefore the specific focus of this report. IY has been evaluated in over 50 studies and proven effective in both clinical and community samples (Menting, Orobio de Castro, \& Matthys, 2013; Webster-Stratton \& Hammond, 1997; Weeland, Chhangur et al., in press). IY intervention effects have been replicated independently (e.g., Scott, Spender, Doolan, Jacobs, \& Aspland, 2001), and results include reductions in externalizing behavior that endure several years after exposure to the program (e.g., Jones, Daley, Hutchings, Bywater, \& Eames, 2008; Posthumus, Raaijmakers, Maassen, Van Engeland, \& Matthys, 2012).

Important to appreciate, however, is that average effect size of IY and most other parenting interventions are small to moderate in magnitude (McCart, Priester, Davies, \& Azen, 2006), with children varying in the degree to which they benefit from the program. In fact, a recent meta-analysis of IY effectiveness chronicled a substantial effect in treatment studies, but a small effect in indicated prevention research on children identified as having minimal but detectable signs or symptoms $(d=.20$, Menting et al., 2013). Even the most successful interventions for externalizing behavior might be effective for only about two-thirds of children (see WebsterStratton \& Hammond, 1997). Such results highlight the need to illuminate potential moderators of intervention efficacy. It seems plausible that such determinants of variation in response to intervention could be genetic in character, as responsiveness to changes in parenting may depend on reward sensitivity. Specifically, the dopaminergic system would seem to play a pivotal role due to its link with 
reward sensitivity and reinforcement learning (Bakermans-Kranenburg \& Van IJzendoorn, 2011).

\section{Differential Susceptibility to Environmental Influences}

Decades of research informed by the diathesisstress model of Person $\times$ Environment interaction (Zuckerman, 1999) made clear that some individuals are more susceptible to the negative effects of exposure to diverse conditions of contextual adversity (e.g., poverty, depressed mother, harsh parenting) and that this enhanced vulnerability to adversity might be a function of their personal characteristics (i.e., temperamental, physiological, or genetic characteristics). Recent theorizing has called attention to the fact that the very individual attributes that appear to make some children more vulnerable to adversity might also make them more likely to benefit from supportive environmental conditions. Indeed, differential-susceptibility theorizing postulates that some children are more developmentally plastic or malleable "for better and for worse" rather than just more likely to succumb to negative rearing conditions (Belsky \& Pluess, 2009, 2013; Belsky et al., 2007; Boyce \& Ellis, 2005).

A growing body of evidence is consistent with this claim (Belsky \& Pluess, 2009, 2013). Especially important for the purposes of this study is research documenting the role of dopaminergic genes in moderating a variety of environmental effects in a for-better-and-for-worse, differential-susceptibilityrelated manner. For example, Foley et al. (2004) found that boys with the MAOA low-activity allele were more likely than their high-activity counterparts to be diagnosed with conduct disorder when exposed to high levels of childhood adversity but were less likely to do so when exposed to low levels of adversity. The polymorphisms selected for inclusion in the work reported herein have been found to moderate environmental effects in Gene $\times$ Environment $(G \times E)$ research in a similar differential-susceptibility-related manner (Belsky \& Pluess, 2013; Van IJzendoorn \& Bakermans-Kranenburg, 2015). The current investigation is therefore specifically conceptualized in such terms rather than in terms of vantage sensitivity - which refers to factors that make some individuals more susceptible to positive exposures but does not make them more susceptible to negative ones (Pluess \& Belsky, 2013).

\section{Why Dopaminergic Genes?}

Dopamine is an excitatory neurotransmitter involved in motivational, attentional, and reward processes. It is heavily expressed in dopaminergic pathways in the brain (e.g., the ventral tegmental area, nucleus accumbens, and prefrontal cortex) where it appears to modulate excitatory signaling (Blum et al., 1996). This signaling plays an important role in reward processing. Different dopaminergic polymorphisms are known to alter reward processing - that makes children and adolescents apparently more or less prone to environmental cues of reward by affecting how much dopamine moves into a synapse or how quickly it is reabsorbed or degraded (Matthys, Vanderschuren, \& Schutter, 2013; Moore \& Depue, 2016). This might influence how susceptible children are to parenting practices based on reward. Here, we focus on the cumulative function of several polymorphisms that are known to affect levels of dopamine signaling in the brain and thereby possibly contribute to individual differences in reward processing: The 7repeat allele of $D R D 4$, the A1 allele of $D R D 2$, the 10-repeat allele of DAT1, the low-activity allele of $M A O A$, and the val allele of COMT.

All the above listed allelic variants have been linked to increased sensitivity to environmental influences in a for-better-and-for-worse manner (Belsky \& Pluess, 2009, 2013). Consider in this regard evidence of Laucht et al. (2007) showing that adolescents carrying the DAT1 10-repeat allele manifested most and least inattention problems when living under high- and low-aversive conditions, respectively, compared to other children. Relatedly, KimCohen et al. (2006) found that boys carrying the $M A O A$ low-activity allele were rated by teachers and mothers as having more mental health problems than other boys when experiencing physical abuse but fewer problems when not mistreated. Notable, in fact, is Bakermans-Kranenburg and Van IJzendoorn's (2011) meta-analysis showing that individual dopamine-related genes moderate diverse environmental effects in a differential-susceptibility-related manner in the case of children under 10 years of age. Just as noteworthy, however, is that $\mathrm{G} \times \mathrm{E}$ results of correlational studies have proven difficult to replicate, and the interpretation of $G \times E$ effects has not always been straightforward (e.g., Duncan \& Keller, 2011).

\section{Gene $\times$ Intervention Interaction}

A major step forward in testing $G \times E$ builds on an experimental paradigm that involves intervention. As such, $G \times I$ (Gene $\times$ Intervention) research has several advantages (Belsky \& Van IJzendoorn, 2015; Van IJzendoorn \& Bakermans-Kranenburg, 
2015). First, it eliminates possible Gene $\times$ Environment correlations $(r \mathrm{GE})$ that plague interpretation of virtually all $\mathrm{G} \times \mathrm{E}$ work (Bakermans-Kranenburg \& Van IJzendoorn, 2015; Chhangur, Weeland, Matthys, \& Overbeek, 2015). Second, G × I research provides a means for establishing differential susceptibility due to its focus on environmental enrichment. Third, standardized interventions afford precise and thus reliable measurement of the environment, thereby reducing measurement error. Fourth, $\mathrm{G} \times \mathrm{I}$ designs provide considerably more statistical power due to the dichotomous parameterization of an environmental factor (i.e., experimental/control) as well as a targeted focus on "at-risk" samples (Bakermans-Kranenburg \& Van IJzendoorn, 2015).

Research on genetic moderation of intervention efficacy is growing following a pioneering study showing that video-feedback intervention designed to reduce externalizing behavior by promoting sensitive parenting and positive discipline proved effective only for children carrying 7-repeat alleles of the DRD4 gene (Bakermans-Kranenburg et al., 2008). More recent research further revealed that children carrying the 7-repeat allele disproportionately benefited from computerized training designed to enhance phonemic awareness (Kegel, Bus, \& van IJzendoorn, 2011) and, separately, text comprehension (Plak, Kegel, \& Bus, 2015). Working with older children-African American adolescents growing up in rural Georgia-Brody, Yu, and Beach (2015) observed that a family-based intervention designed to prevent, among other things, substance use proved effective principally for teenagers carrying this same putative plasticity allele. Most notably, Van IJzendoorn and Bakermans-Kranenburg (2015) meta-analysis found that genetic moderation of efficacy proved to be the norm, even across interventions of varying intensity (Van IJzendoorn \& Bakermans-Kranenburg, 2015). One limitation of virtually all $G \times I$ work to date, however, is its focus on single candidate genes, thus failing to do justice to the polygenic nature of development.

\section{Current Study}

The research reported herein evaluates the genetic moderation of the efficacy of the IY program. Rather than focusing on a single candidate gene, we employ a systems' approach (Nikolova, Ferrell, Manuck, \& Hariri, 2011), creating a dopaminergic polygenetic composite (based on the allelic variants already highlighted). Following Belsky and Beaver (2011), we gave children one point for each polymorphism for which they had at least one putative plasticity allele (i.e., 0/1 scoring, range: $0-5$ ). We predicted that children scoring highest on the polygenic index would show the greatest decrease in externalizing behavior in response to the IY intervention; and that this would be especially so when parents evinced substantial rather than limited improvement in their positive parenting behavior in response to intervention. In other words, it would be children carrying many rather than few plasticity alleles whose parents changed the most who would benefit most from the IY program. After evaluating these predictions with all children, we conducted a series of sensitivity analyses based on appreciation that (a) inclusion of children who vary in their race/ ethnicity could be problematic when genetics are a focus of interest (Propper, Willoughby, Halpern, Carbone, \& Cox, 2007) and (b) results can differ when only cases with complete data are studied versus when an intention-to-treat design is employed. In all analyses, $G \times I$ effects were tested separately for boys and girls because one of the polymorphisms included in our polygenic index, the $M A O A$, is sex linked (Byrd \& Manuck, 2014).

\section{Method}

\section{The ORCHIDS Study}

Data for the research reported here come from the ORCHIDS study (Observational Randomized Controlled Trial on Childhood Differential Susceptibility) conducted in the Netherlands. Data were collected in two cohorts from November 2012-2013 through November 2013-2014. Detailed information about the sample and sampling appears elsewhere (Chhangur, Weeland, Overbeek, Matthys, \& Orobio de Castro, 2012; Weeland, Chhangur et al., in press). Using a randomized control design, the ORCHIDS study addresses the differential effectiveness-across children with varying temperamental and genetic characteristics - of the IY program in reducing externalizing behavior in 4- to 8-year-old children showing moderate to high levels of such problems by enhancing a warm parent-child relationship through child-directed play; coaching of social, emotional, and academic skills; praise and rewards; effective limit setting; and handling (e.g., ignore and time-out techniques).

\section{Sample}

Participants were recruited in two cohorts via two Dutch regional health care organizations. 
Parents of 20,084 children aged 4-8 were mailed a questionnaire to assess frequency of externalizing child behavior (i.e., screening stage), resulting in 5,876 questionnaires returned in a timely manner (response rate: $22.5 \%$ ). Children scoring at or above the 75th percentile on the Eyberg Child Behavior Inventory (ECBI) intensity score scale $(n=1,524)$ were eligible for the randomized controlled trial (RCT). If parents reported moderate to high levels of externalizing behavior of multiple children within a family, the child with highest ECBI Intensity score was invited. A total of 1,393 mother-child or father-child dyads were thus invited to participate, and $61 \%$ of these to-be-recruited families were reached; $46 \%$ of the latter $(N=387)$ agreed to participate. ECBI Intensity scores from screened families $(M=2.65, S D=0.52)$ differed from invited families, $\quad M=3.59, \quad S D=0.46 ; \quad t(5,872)=-89.57$, $p<.001$, and from those who agreed to participate, $M=3.64, \quad S D=0.47 ; \quad t(5,872)=-28.90, \quad p<.001$, though those who agreed to participate scored somewhat higher than those invited but did not participate, $t(1,522)=-2.54, p=.01$.

Cheek cells were collected for DNA assaying from 385 children (failed genotyping assay: $n=2$ ), with the primary analysis sample consisting of 341 of these children and their parents; 44 families randomized to the intervention group are excluded from the primary analysis because they did not attend any of the intervention sessions. Notably, those excluded $(M=3.66)$ did not differ from those included on the ECBI Intensity score $(M=3.71, p=.56)$. Most parents participating in the RCT were mothers (89.4\%), Caucasian (90.5\%), and well educated (23.3\% vocational training, $42.9 \%$ higher vocational training or university). Intervention and control groups did not differ on sample characteristics (i.e., age, child age, gender, number of siblings, educational level, ethnicity) and baseline externalizing behavior (see Table 1).

\section{Design and Procedure}

Two months following screening, trained research assistants conducted pretest home visits to collect DNA and observational data from the child, questionnaires to measure child externalizing behavior, and positive parenting behavior were emailed to parents a week earlier. Subsequently, families were randomly assigned (ratio: 1:1) to control $(n=190)$ or intervention group $(n=197)$; recall that 44 families allocated to intervention did not attend any sessions and were thus excluded from
Table 1

Sociodemographic Information and Initial Level of Externalizing Behavior for Control and Intervention Groups by Gender

\begin{tabular}{|c|c|c|c|c|c|c|}
\hline \multirow{3}{*}{$\frac{\text { Boys }}{\text { Age child (years) }}$} & \multicolumn{2}{|c|}{ Total } & \multicolumn{2}{|c|}{$\begin{array}{l}\text { Control } \\
\text { group }\end{array}$} & \multicolumn{2}{|c|}{$\begin{array}{l}\text { Interven- } \\
\text { tion group }\end{array}$} \\
\hline & \multicolumn{2}{|c|}{$(N=190)$} & \multicolumn{2}{|c|}{$(n=100)$} & \multicolumn{2}{|c|}{$(n=90)$} \\
\hline & 6.3 & 1.34 & 6.4 & 1.38 & 6.1 & 1.29 \\
\hline Age parent (years) & 37.9 & 4.70 & 38.0 & 4.63 & 37.0 & 4.81 \\
\hline$\%$ mother & 92.6 & & 94.0 & & 91.1 & \\
\hline Number of children & 2.3 & 0.82 & 2.3 & 0.77 & 2.3 & 0.89 \\
\hline \multicolumn{7}{|l|}{ Education mother } \\
\hline \% low & 19.5 & & 19.0 & & 20.0 & \\
\hline$\%$ medium & 27.4 & & 26.0 & & 28.9 & \\
\hline$\%$ high & 52.6 & & 45.0 & & 50.0 & \\
\hline \multicolumn{7}{|l|}{ Education father } \\
\hline$\%$ low & 21.1 & & 21.0 & & 21.1 & \\
\hline$\%$ medium & 28.4 & & 24.0 & & 33.3 & \\
\hline$\%$ high & 47.9 & & 51.0 & & 44.4 & \\
\hline$\%$ Caucasian mother & 91.5 & & 91.0 & & 91.1 & \\
\hline$\%$ Caucasian father & 90.5 & & 91.0 & & 88.9 & \\
\hline$\%$ single parent & 9.5 & & 7.0 & & 12.2 & \\
\hline Externalizing behavior & 3.83 & 0.50 & 3.77 & 0.51 & 3.89 & 0.49 \\
\hline Girls & \multicolumn{2}{|c|}{$(N=151)$} & \multicolumn{2}{|c|}{$(n=90)$} & \multicolumn{2}{|c|}{$(n=61)$} \\
\hline Age child (years) & 6.3 & 1.25 & 6.2 & 1.18 & 6.4 & 1.35 \\
\hline Age parent (years) & 38.4 & 4.97 & 39.3 & 4.99 & 38.4 & 4.98 \\
\hline$\%$ mother & 89.4 & & 88.0 & & 90.2 & \\
\hline Number of children & 2.2 & 0.76 & 2.0 & 0.18 & & \\
\hline \multicolumn{7}{|l|}{ Education mother } \\
\hline$\%$ low & 20.7 & & 18.9 & & 23.3 & \\
\hline$\%$ medium & 27.3 & & 30.0 & & 23.3 & \\
\hline$\%$ high & 51.3 & & 50.0 & & 53.3 & \\
\hline \multicolumn{7}{|l|}{ Education father } \\
\hline \% low & 31.3 & & 32.2 & & 30.0 & \\
\hline$\%$ medium & 23.3 & & 24.4 & & 21.7 & \\
\hline \% high & 42.9 & & 41.1 & & 45.0 & \\
\hline$\%$ Caucasian mother & 93.4 & & 95.6 & & 90.2 & \\
\hline$\%$ Caucasian father & 92.1 & & 95.6 & & 86.9 & \\
\hline$\%$ single parent & 8.0 & & 5.6 & & 11.7 & \\
\hline Externalizing behavior & 3.56 & 0.54 & 3.53 & 0.49 & 3.62 & \\
\hline
\end{tabular}

Note. None of the groups differed significantly on sociodemographic characteristics and initial parent-reported externalizing behavior with independent samples $t$-test or chi-square test. Low $=$ completed middle or high school; medium $=$ completed vocational training; high $=$ completed higher vocational training or university.

the primary analyses. Approximately 4 and 8 months after the pretest (i.e., posttest, follow-up), parents again completed the questionnaires and observations were made of child externalizing behavior. The Institutional Review Broad in the Netherlands (METC UMC Utrecht, protocol number 11-320/K) approved the study. 


\section{Incredible Years Parent Training}

The IY program uses a collaborative group approach; group leaders serve as facilitators rather than experts while seeking to empower parents. Issues and topics addressed include the importance of child-directed play, social and emotion coaching, the use of praise to reward and incentives to motivate appropriate behavior, and the importance of consistency in the use of noncorporal disciplinary practices. This trial involved 14 weekly sessions in which parents watched and discussed video vignettes of parent-child interactions, engaged in role playing, and discussed family experiences in small (sub)groups. More specifically, following each vignette, group leaders asked questions to stimulate discussion on (in)effective parenting behavior and alternative approaches. Before sessions, parents received exercises to practice at home, read relevant literature, and practiced behavior management skills with their child. A final and 15th session took place a month following the 14th session, serving as a "booster" to consolidate intervention effects by repeating, discussing, and practicing skills. The intervention groups consisted of 8-15 parents. Parents attended an average of 11 of the 15 sessions $(M=10.85, S D=3.95)$. Although the parent who filled out the questionnaires attended the sessions, the other parent was allowed to do so as well. Every group was led by two group leaders. Main leaders had a background in clinical child psychology, had experience running IY groups before the study commenced, and were officially certified group leaders. All leaders received 2-hr supervision sessions at least three times across the 14-week period. Besides these, regular intersession meetings between group leaders took place (see also Weeland, Chhangur et al., in press).

\section{Measures}

\section{Parent-Reported Externalizing Behavior}

The ECBI (Eyberg \& Pincus, 1999), used at screening, pretest, posttest, and follow-up, assessed child externalizing problems. One of the instrument's two scales is the focus of in this report. This Intensity subscale consists of 36 items tapping frequency of externalizing behavior using a 7-point Likert-type scale $(0=$ never to $7=$ always $)$. Example items are: "Does not obey house rules" and "Whines." The internal consistencies (Cronbach's alpha) were $.85, .86$, and .88 at pretest, posttest, and follow-up, respectively.

\section{Observed Externalizing Behavior}

The Dyadic Parent-Child Interaction Coding System was used to measure observed externalizing behavior (Robinson \& Eyberg, 1981; Webster-Stratton, 1989). At all three measurement times, parentchild dyads were observed for $20 \mathrm{~min}$, divided into 4- to 5-min episodes: (a) free play (i.e., to get used to being videotaped), (b) child-directed play (i.e., child picked a toy and directed the session), (c) parent-directed play (i.e., parent picked a toy and directed the session), and (d) clean-up (i.e., parent instructed child to clean-up). In the latter three episodes, negative child behavior was coded using five categories: indirect command noncompliance, direct command noncompliance, cry-whine-yell, destructive behavior, and physical negative behavior. A total summed score based on these three episodes and reflecting the frequency of these behaviors served as the observational index of externalizing behavior. The interepisodes correlations among within-episodes composites were significantly correlated at pretest $(r=.11-.48)$, posttest $(r=.25-.40)$, and follow-up $(r=.17-.38)$ measurement occasions.

Observations were coded by six trained research assistants blind to condition and measurement wave. Monthly calibration meetings were held to prevent observer drift. A random $20 \%$ of observations were independently coded by two coders unaware of which observations would be used to assess interobserver agreement. Interrater reliability, based on intraclass correlation, were $.83, .82$, and .70 at pretest, posttest, and follow-up, respectively.

\section{Parent-Reported Positive Behavior}

The Parent Practices Inventory (PPI; WebsterStratton, 2001a), used at all measurement occasions, assessed parenting skills and discipline styles. Although positive parenting behavior was also observed, the fact that little variance was detected in the observational data precluded us from using this measure as an outcome. The PPI consists of 15 scales, each containing several items related to how parents typically respond to their child's appropriate and inappropriate behavior (measured using a 7-point Likert-type scale: $0=$ not likely at all/never to 7 = very likely/always). For this report, praise and incentives (11 items) and positive verbal discipline (9 items) were combined to create an index of positive parenting behavior (e.g., "When my child complete chores I praise him," "When my child refuses do to something I discuss the problem with him," and "When my child behaves well, it is important 
to set up rewards or privileges"). Cronbach's alphas were .73, .76, and .79 at pretest, posttest, and follow-up, respectively.

\section{Genotyping}

Genotyping was conducted at BaseClear laboratories, Leiden, The Netherlands, using well-established methods. Buccal swabs collected from children were incubated in lysis buffer $(100 \mathrm{mM}$ $\mathrm{NaCl}, 10 \mathrm{mM}$ Ethylenediaminetetraacetic acid (EDTA), $10 \mathrm{mM}$ Tris $\mathrm{pH} 8,0.1 \mathrm{mg} / \mathrm{ml}$ proteinase $\mathrm{K}$, and $0.5 \% \mathrm{w} / \mathrm{v}$ sodium dodecyl sulfate (SDS)) until further processing. Genomic DNA was isolated from the samples using the Chemagic buccal swab kit on a Chemagen Module I workstation (Chemagen Biopolymer-Technologie AG, Baesweiler, Germany). All analyses were performed automatically using specialized genotyping software. Each plate's results were checked by a laboratory worker (and checked by a second worker); those showing notable deviations or failings were repeated. As a control check, each 96 wells plate contained one blank and analyses were continued only if the blank showed a negative result. Overall, genotyping yielded a success rate of approximately $99 \%$ or higher for the five polymorphisms central to this report.

\section{DRD2 and COMT}

To determine the SNPs of DRD2 rs1800497 and COMT rs4680, $1 \mu \mathrm{l}$ of the isolated samples were analyzed using TaqMan chemistry (Cat. \#4351379, Applied Biosystems, Leiden, The Netherlands). Samples were run on an ABI-7500 Real-Time PCR instrument and data were analyzed using 7500 System SDS software (Baseclear BV Leiden, The Netherlands). DRD2 genotypes $(n=247 \mathrm{~A} 2 / \mathrm{A} 2, n=122$ A2/A1, $n=14$ A1/A1) were in Hardy-Weinberg equilibrium (HWE), $\chi^{2}(1, n=383)=0.05, p=.82$ $(n=4$ no genotyping); COMT genotypes $(n=90$ met $/ \mathrm{met}, n=185 \mathrm{met} / \mathrm{val}, n=108 \mathrm{val} / \mathrm{val})$ were in HWE, $\chi^{2}(1, n=383)=0.04, p=.84 \quad(n=4$ no genotyping).

\section{DRD4}

For all variable number tandem repeat (VNTR) polymorphisms (i.e., DRD4, DAT1, and MAOA), $1 \mu \mathrm{l}$ of PCR product was mixed with $0.3 \mu \mathrm{l}$ LIZ-500 size standard (Applied Biosystems Leiden, The Netherlands) and $11.7 \mu \mathrm{l}$ formamide (Applied Biosystems) and run on a $\mathrm{AB} 3730$ genetic analyzer set up for fragment analyses with $50 \mathrm{~cm}$ capillaries. Results were analysed using GeneMarker software (Softgenetics). The region of interest from the DRD4 gene was amplified by PCR using a FAM-labeled primer 5'-GCGACTACGTGGTCTACTCG-3' and a reverse primer 5'-AGGACCCTCATGGCCTTG-3'. Typical PCR contained between 10 and $100 \mathrm{ng}$ genomic DNA templates, 10 pmol of forward and reverse primers. PCR was carried out in the presence of $7.5 \%$ Dimethyl sulfoxide (DMSO), $5 \times$ buffer supplied with the enzyme, and with $1.25 \mathrm{U}$ of LongAmp Taq DNA Polymerase (NEB) in a total volume of $30 \mu \mathrm{l}$ using the following cycling conditions: initial denaturation step of $10 \mathrm{~min}$ at $95^{\circ} \mathrm{C}$, followed by 27 cycles of $30 \mathrm{~s}$ at $95^{\circ} \mathrm{C}, 30 \mathrm{~s}$ at $60^{\circ} \mathrm{C}$, $60 \mathrm{~s}$ at $65^{\circ} \mathrm{C}$, and a final extension step of $10 \mathrm{~min}$ at $65^{\circ} \mathrm{C}$. Genotypes $(n=248$ [no 7-repeat/no 7-repeat], $n=119$ [no 7-repeat/7-repeat], $n=8$ [7-repeat/7repeat]) were in $\operatorname{HWE}, \chi^{2}(1, N=375)=2.11$, $p=.15$ ( $n=12$ no genotyping).

\section{DAT1}

The region of interest from the DAT1 gene was amplified by PCR using a FAM-labeled primer $5^{\prime}$ TGTGGTGTAGGGAACGGCCTGAG- $3^{\prime}$ and a reverse primer 5'-CTTCCTGGAGGTCACGGCT CAAGG-3'. Typical PCR contained between 10 and $100 \mathrm{ng}$ genomic DNA templates, 10 pmol of forward and reverse primers. PCR was carried out in the presence of 3.3\% DMSO with $1.25 \mathrm{U}$ of LongAmp Taq DNA Polymerase (NEB) in a total volume of $30 \mu \mathrm{l}$ using the following cycling conditions: initial denaturation step of $5 \mathrm{~min}$ at $95^{\circ} \mathrm{C}$, followed by 29 cycles of $30 \mathrm{~s}$ at $95^{\circ} \mathrm{C}, 30 \mathrm{~s}$ at $68^{\circ} \mathrm{C}, 60 \mathrm{~s}$ at $65^{\circ} \mathrm{C}$, and a final extension step of $5 \mathrm{~min}$ at $65^{\circ} \mathrm{C}$. Genotypes ( $n=31$ [no 10-repeat/no 10-repeat], $n=148$ [no 10-repeat/10-repeat], $n=203$ [10-repeat/10repeat]) were in HWE, $\chi^{2}(1, N=382)=0.03$, $p=.86$ ( $n=5$ no genotyping).

\section{$M A O A$}

The region of interest from the MAOA gene was amplified by PCR using a FAM-labeled MR primer 5'-GGATAACAATTTCACACAGG-3', forward primer 5'-ggataacaatttcacacaggACAGCCTGACCGTG GAGAAG-3', and a reverse primer 5'-GGAC CTGGGCAGTTGTGC-3'. Typical PCR contained between 10 and $100 \mathrm{ng}$ genomic DNA templates, 1 pmol of forward primer, and 10 pmol of labeled MR and reverse primers. PCR was carried out in the presence of $5 \%$ DMSO with $1.25 \mathrm{U}$ of LongAmp Taq DNA Polymerase (NEB) in a total volume of 
$30 \mu \mathrm{l}$ using the following cycling conditions: initial denaturation step of $5 \mathrm{~min}$ at $94^{\circ} \mathrm{C}$, followed by 38 cycles of $30 \mathrm{~s}$ at $94^{\circ} \mathrm{C}, 30 \mathrm{~s}$ at $55^{\circ} \mathrm{C}, 30 \mathrm{~s}$ at $72^{\circ} \mathrm{C}$, and a final extension step of $4 \mathrm{~min}$ at $72^{\circ} \mathrm{C}$. Genotypes for boys were $n=80$ low/low and $n=123$ high/high ( $n=11$ no genotyping). Because boys have only one $X$ chromosome, only girls were included in the HWE calculation. Genotypes for girls $(n=23$ low/low, $n=75$ low /high, $n=96$ high/high) were in HWE, $\chi^{2}(1, N=167)=0.13$, $p=.73$ ( $n=6$ no genotyping).

\section{Polygenic Scoring}

Each polymorphism was assigned a point if the child was carrying at least one of the putative plasticity alleles; these values were then summed to create a polygenetic plasticity index ranging from 0 to 5 . To create groups of reasonable size for statistical analysis, children scoring low (0-2) and high (3-5) on this polygenic index were distinguished. The distribution of those scoring low or high on the polygenic index of plasticity was, for boys, respectively, $23.2 \%(n=44)$ and $29.5 \%(n=56)$ in the control group and $17.9 \%(n=34)$ and $29.5 \%(n=56)$ in the intervention group. The comparable distribution for girls was, respectively, $19.9 \% \quad(n=30)$ and $39.7 \%(n=60)$ in the control group and $12.6 \%$ $(n=19)$ and $27.8 \%(n=42)$ in the intervention group.

\section{Results}

Latent growth curve modeling (LGCM) in Mplus (Muthén \& Muthén, 1998) was performed initially on all children, irrespective of their race/ethnicity and separately for boys and girls, to assess the development of externalizing behavior across pretest, posttest, and follow-up assessments. Because individual growth is estimated for each child, LGCM is an excellent approach for examining variation in the development of externalizing behavior while considering whether certain predictors are associated with differential trajectories. Full information maximum likelihood was used to treat missing data. Experimental condition (i.e., intervention vs. control) and the polygenetic plasticity index (i.e., more vs. few) served as predictors in the primary model. Because the intervention was focused on inducing positive parenting behavior, and presumed to affect children by changing parenting, we used a Parallel Process LGCM to evaluate whether genetically moderated intervention effects were more pronounced when parents increased more rather than less in positive parenting behavior (i.e., Gene $\times$ Slope positive parenting on slope child externalizing behavior; Cheong, MacKinnon, \& Khoo, 2003). Model fit is considered good if the root mean square error of approximation (RMSEA) is $<.08$ and mediocre if $<.10$. Comparative fit index (CFI) values should be $>.95$ (Hu \& Bentler, 1999).

Genetic, Intervention, and Gene $\times$ Intervention Effects

Parent-Reported Child Externalizing Behavior

With regard to specific effects, we consider first effects on problem behavior at pretest before turning attention to change over time (i.e., slope). Inspection of Table 2 indicates that for both boys and girls there were no significant main effects of treatment condition (i.e., IY vs. control) on the pretest intercept (boys: $\beta_{0}=-.036, p=.65$; girls: $\left.\beta_{0}=-.001, p=.99\right)$, thereby indicating that the

Table 2

$G \times E$ Interactions Between Condition and Polygenetic Plasticity Index in the Development of Reported Externalizing Behavior by Gender

\begin{tabular}{|c|c|c|c|c|c|c|}
\hline Predictor & Intercept & Slope & $\chi^{2}(d f)$ & CFI & RMSEA & $p$ value \\
\hline \multicolumn{7}{|l|}{ Male $(n=190)$} \\
\hline Condition & $-.036(.08)$ & $-.041(.02)^{*}$ & $6.70(3)$ & 0.99 & .08 & \\
\hline Polygenetic plasticity alleles & $-.030(.07)$ & $.010(.01)$ & & & & \\
\hline Condition $\times$ Polygenetic Plasticity Index & $-.022(.15)$ & $-.183(.07)^{* *}$ & $2.24(4)$ & 1.00 & $<.001$ & .84 \\
\hline \multicolumn{7}{|l|}{ Female $(n=151)$} \\
\hline Condition & $-.001(.08)$ & $-.055(.03)^{*}$ & $6.45(3)$ & 0.98 & .09 & \\
\hline Polygenetic plasticity alleles & $-.163(.07)^{*}$ & $-.005(.02)$ & & & & \\
\hline Condition $\times$ Polygenetic Plasticity Index & $.038(.17)$ & $.085(.10)$ & $7.06(4)$ & 0.98 & .07 & \\
\hline
\end{tabular}

Note. As $\chi^{2}<d f$, the CFI is set to 1.0 and RSMEA to $<.001$, which makes it sufficient to read off whether the $p$ value is not significant. Condition: $0=$ control group; 1 = intervention group. $\mathrm{CFI}=$ comparative fit index; RMSEA = root mean square error of approximation. $* p<.05 . * * p<.01$. 
randomization process proved effective in equating groups for initial levels of problem behavior. For girls there was a significant main effect of the polygenic index of plasticity on the pretest intercept $\left(\beta_{0}=-.163, p=.03\right)$, indicating that girls who scored high on the index had fewer problems initially. Turning to the prediction of slope, treatment condition proved significant in the case of both boys $\left(\beta_{1}=-.041, p=.04\right)$ and girls $\left(\beta_{1}=-.055, p=.05\right)$, revealing that parent-reported externalizing behavior decreased more in the intervention than control group. The models of intercept and slope showed a relatively good fit for boys $\left(\chi^{2}[d f=3\right.$, $n=190]=6.70$, CFI $=0.99$, RMSEA $=.08)$, but a mediocre fit for girls $\left(\chi^{2}[d f=3, n=151]=6.45\right.$, $\mathrm{CFI}=0.98$, RMSEA $=.09$ ).

In a second phase of modeling, the Condition $\times$ Polygenic Index interaction term was included. This two-way interaction proved significant for slope for boys $\left(\beta_{1}=-.183, p=.01 ; \chi^{2}[d f=4\right.$, $n=190]=2.21$, CFI $=1.00$, RMSEA $<.001$, partial $\left.\eta^{2}=.04\right)$, though not for girls $\left(\beta_{1}=.085, p=.37\right.$; $\chi^{2}[d f=4, n=151]=7.06, \mathrm{CFI}=0.98, \mathrm{RMSEA}=.07$, partial $\left.\eta^{2}=.00\right)$. Thus, the intervention was most effective in decreasing parent-reported externalizing behavior for boys with high polygenic scores, particularly by time of follow-up (partial $\eta^{2}=.20$; see Figure 1). A series of planned comparisons testing the hypothesis that the high polygenic index boys in the intervention group would benefit most from the intervention revealed that in comparison to all other boys this hypothesized highly susceptible subgroup of children assigned to the intervention (a) did not differ from all other boys on parent-reported externalizing behavior at pretest, $F(1,180)=1.00, p=.40$, but (b) scored significantly lower at follow-up, $F(1$, $180)=3.78, p=.01$ and thus (c) evinced significantly greater reduction (i.e., change) from pretest to follow-up than all other boys, $F(1,180)=5.29, p=.001$.

\section{Observed Child Externalizing Behavior}

Inspection of Table 3 indicates that the main effect of condition on the pretest intercept of observed externalizing behavior proved significant $\left(\beta_{0}=.196, p=.01\right)$, as did that for slope $\left(\beta_{1}=-.108\right.$, $p=.03)$, but only for boys $\left(\chi^{2}[d f=5\right.$, $n=188]=4.92, \mathrm{CFI}=1.00, \quad \mathrm{RMSEA}=.02$, partial $\eta^{2}=.05$ ), not for girls (intercept: $\beta_{0}=.020, p=.81$; slope: $\beta_{1}=-.028, p=.56 ; \chi^{2}[d f=3, n=151]=.001$, CFI $=1.00$, RMSEA $=<.001$, partial $\eta^{2}=.00$ ). Compared to the control group, IY boys showed not only more externalizing behavior at pretest but also the steepest decrease over time when controlling for baseline differences. Both the main effect of the polygenic index and the Condition $\times$ Polygenic Index interaction term proved nonsignificant for both boys and girls (boys: $\beta_{1}=-.003, p=.98, \chi^{2}[d f=6$, $n=188]=4.92, \mathrm{CFI}=1.00, \mathrm{RMSEA}=<.001$, partial $\eta^{2}=.00 ; \quad$ girls: $\quad \beta_{1}=-.101, \quad p=.30, \quad \chi^{2}[d f=4$, $n=151]=1.12$, CFI $=1.00$, RMSEA $=<.001$, partial $\eta^{2}=.00$; see Table 3). These latter results indicate

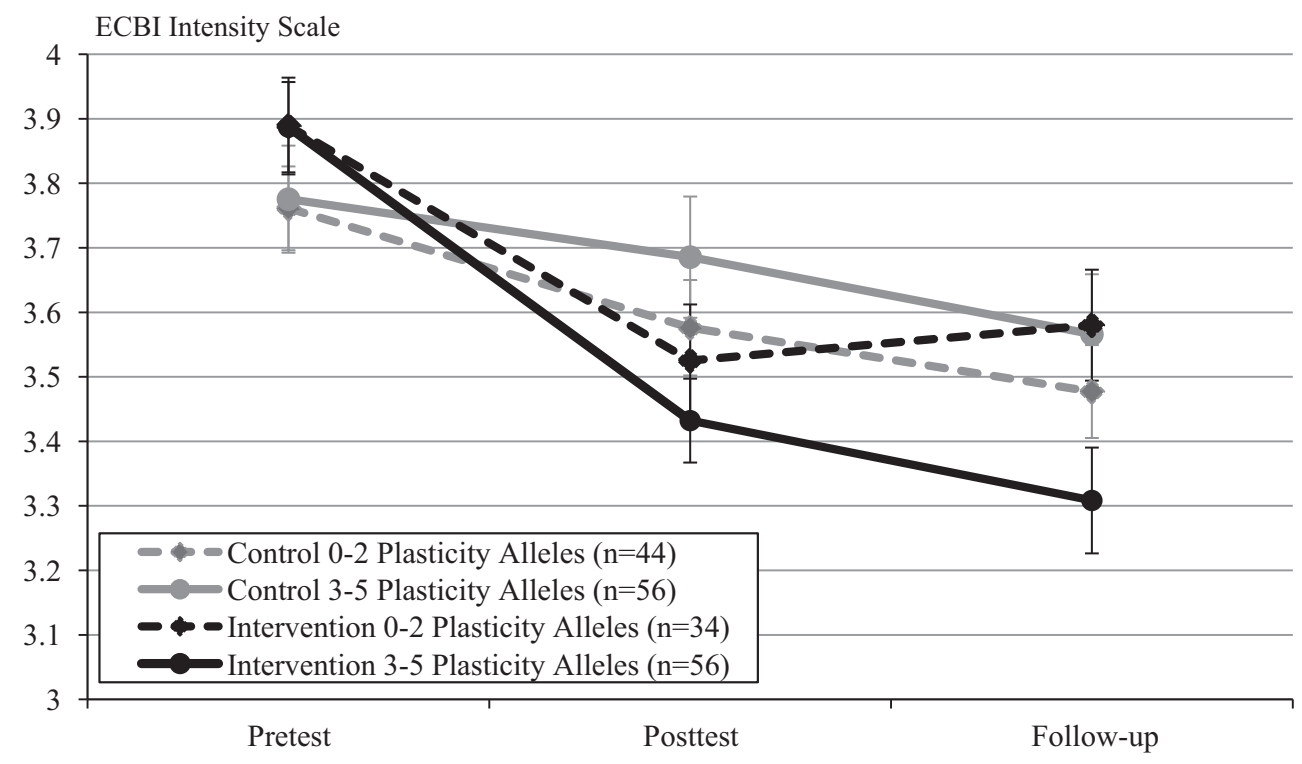

Figure 1. Development of parent-reported externalizing behavior (as indicated by scores on the Eyberg Child Behavior Inventory [ECBI] Intensity Score scale) across pretest, posttest, and follow-up for control and intervention groups with $0-2$ putative polygenetic plasticity alleles or 3-5 such alleles. 
Table 3

$G \times E$ Interactions Between Condition and Polygenetic Plasticity Index in the Development of Observed Externalizing Behavior by Gender

\begin{tabular}{|c|c|c|c|c|c|c|}
\hline Predictor & Intercept & Slope & $\chi^{2}(d f)$ & CFI & RMSEA & $p$ value \\
\hline \multicolumn{7}{|l|}{ Male $(n=188)$} \\
\hline Condition & $.196(.08)^{* *}$ & $-.108(.05)^{*}$ & $5.51(5)$ & 0.95 & .02 & \\
\hline Polygenetic plasticity alleles & $-.045(.08)$ & $-.004(.05)$ & & & & \\
\hline Condition $\times$ Polygenetic Plasticity Index & $.005(.15)$ & $-.003(.10)$ & $4.92(6)$ & 1.00 & $<.001$ & .48 \\
\hline \multicolumn{7}{|l|}{ Female $(n=151)$} \\
\hline Condition & $.020(.09)$ & $-.028(.05)$ & $0.01(3)$ & 1.00 & $<.001$ & .99 \\
\hline Polygenetic plasticity alleles & $.002(.08)$ & $-.016(.05)$ & & & & \\
\hline Condition $\times$ Polygenetic Plasticity Index & $.117(.17)$ & $-.101(.10)$ & $1.12(4)$ & 1.00 & $<.001$ & .89 \\
\hline
\end{tabular}

Note. As $\chi^{2}<d f$, the CFI is set to 1.0 and RSMEA to $<.001$, which makes it sufficient to read off whether the $p$ value is not significant. Condition: $0=$ control group; 1 = intervention group. $\mathrm{CFI}=$ comparative fit index; RMSEA = root mean square error of approximation. $* p<.05 . * * p<.01$.

that children's genetic makeup neither predicted their observed externalizing behavior nor moderated the effect of the intervention on this behavior.

The complementary figures for observed externalizing behavior in boys and parent-reported and observed externalizing behavior in girls are shown in the Supporting Information.

\section{Gene $\times$ Positive Parenting Change}

As a preliminary step before evaluating whether the $G \times I$ effects would prove most pronounced when parents evinced the most increase in positive parenting, we evaluated whether, in general, parents assigned to the experimental group increased more in positive parenting than those assigned to the control group. This expectation was confirmed. Although condition proved nonsignificant for pretest intercept of reported positive parenting behavior $\left(\beta_{0}=.131, p=.13\right)$, it was significant for slope $\left(\beta_{1}=.141, \quad p=.001 ; \quad \chi^{2}[d f=12, \quad n=190]=32.42\right.$, CFI $=0.96$, RMSEA $=.10$ ). Thus, compared to the control group, IY parents showed more improvement in positive parenting behavior over time.

To examine whether the effect of this change in positive parenting on change in boys' externalizing behavior was moderated by the polygenetic dopaminergic index, we used the continuous parenting slope variable reflecting change over time in positive parenting behavior to formulate a two-way interaction term involving it and the polygenetic index. This two-way interaction proved significant in predicting change (i.e., slope) in reported externalizing behavior $\left(\beta_{1}=-.881, p=.04\right)$. To graphically depict this interaction, we created two control subgroups (high and low polygenic index) and four intervention subgroups, the latter reflecting whether boys had a high or low polygenic score combined with whether their parent increased a lot or a little in positive parenting behavior: low polygenic-low positive parenting increase $(n=14)$, low polygenetic-high positive parenting increase $(n=18)$, high polygenic-low positive parenting increase $(n=20)$, and high polygenic-high positive parenting increase $(n=38)$. Inspection of Figure 2 reveals that boys with high scores on the polygenic plasticity index whose parents increased most in positive parenting evinced the greatest decline in parent-reported externalizing behavior; although note that the individual slope for boys scoring high on the polygenetic index whose parents showed less improvement in parenting was also significant.

\section{Sensitivity Analyses}

As a robustness check, a final series of analyses were undertaken (see Table 4). These sought to determine whether the significant results reported pertaining to the genetic moderation of intervention efficacy in the case of boys would hold under varying sampling and design conditions, appreciating that (a) inclusion of children who vary in their race/ ethnicity could be problematic when studying $\mathrm{G} \times \mathrm{E}$ (Propper et al., 2007) and (b) results may differ when only analyzing complete (i.e., completer only) versus intention-to-treat data. The previously documented $G \times I$ effects on the slope of reported externalizing behavior proved significant in all sensitivity analyses: Caucasian boys only with complete data $\left(\beta_{1}=-.149, p=.05\left(\chi^{2}[d f=4, n=168]=2.92\right.\right.$, $\mathrm{CFI}=1.00$, RMSEA $=<.001)$, all boys with intention-to-treat data $\left(\beta_{1}=-.184, p=.01 ; \quad \chi^{2}[d f=4\right.$, $n=210]=4.92, \quad$ CFI $=1.00, \quad$ RMSEA $=.03), \quad$ and Caucasian boys only with intention-to-treat data $\left(\beta_{1}=-.168, \quad p=.02 ; \quad \chi^{2}[d f=4, \quad n=185]=6.13\right.$, CFI $=0.99, \quad$ RMSEA $=.05)$. Similarly, as the data 
ECBI Intensity Scale

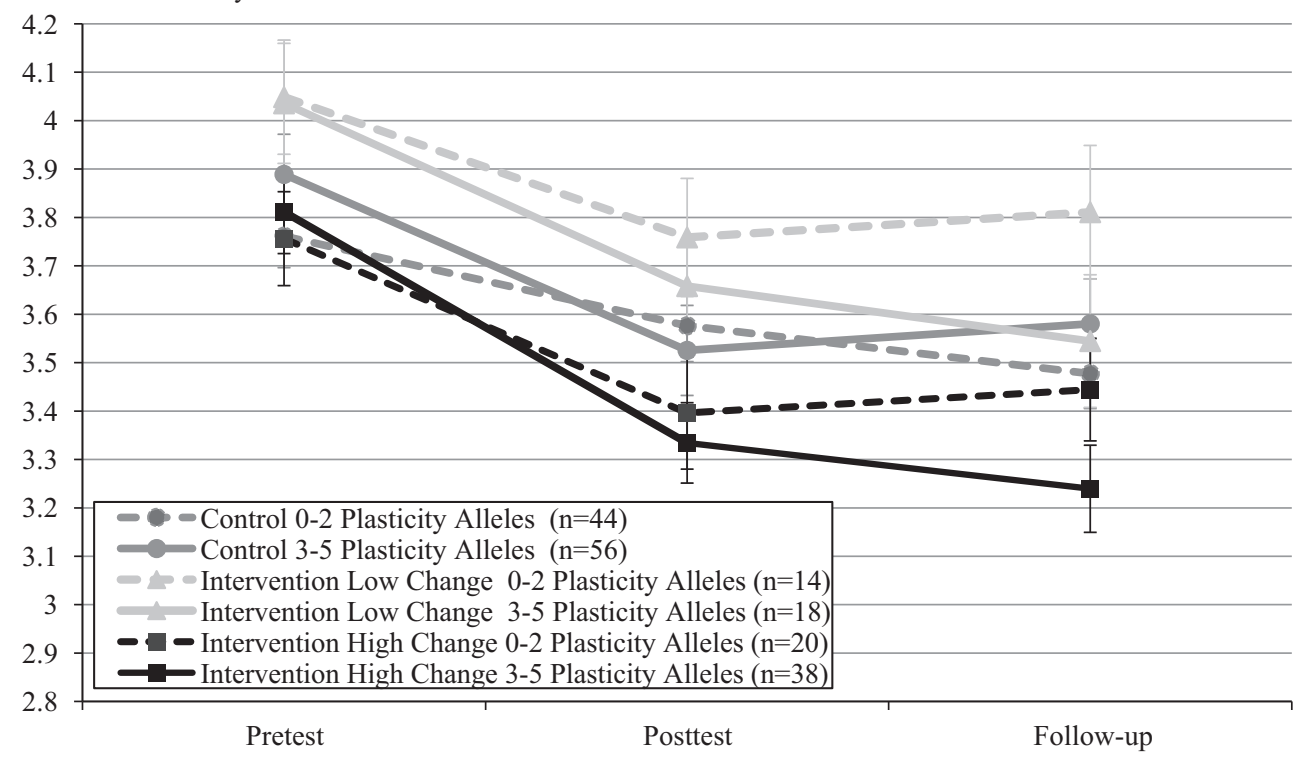

Figure 2. Development of parent-reported externalizing behavior (as indicated by scores on the Eyberg Child Behavior Inventory [ECBI] Intensity Score scale) across pretest, posttest, and follow-up for intervention group with low or high increase in positive parenting (as indicated by slope scores on the construct of Positive Parenting derived from the Parent Practices Inventory [PPI] and boys with 0-2 putative polygenetic plasticity alleles or 3-5 such alleles.

Table 4

Summary of the Effects of Concern: Sensitivity Analyses

\begin{tabular}{|c|c|c|c|c|c|c|c|c|}
\hline & \multirow{2}{*}{\multicolumn{2}{|c|}{$\begin{array}{l}\text { All boys: Complete data } \\
\qquad(n=190)\end{array}$}} & \multicolumn{6}{|c|}{ Sensitivity analyses } \\
\hline & & & \multicolumn{2}{|c|}{$\begin{array}{l}\text { Caucasian boys only: } \\
\text { Complete data }(n=168)\end{array}$} & \multicolumn{2}{|c|}{$\begin{array}{l}\text { All boys: Intention-to-treat } \\
\text { data }(n=210)\end{array}$} & \multicolumn{2}{|c|}{$\begin{array}{l}\text { Caucasian boys only: Inten- } \\
\text { tion-to-treat data }(n=185)\end{array}$} \\
\hline & Intercept & Slope & Intercept & Slope & Intercept & Slope & Intercept & Slope \\
\hline \multicolumn{9}{|c|}{ Intervention effect on externalizing behavior: } \\
\hline Reported $^{\mathrm{a}}$ & $-.036(.08)$ & $-.041(.02)^{*}$ & $-.011(.08)$ & $-.035(.02)$ & $-.004(.08)$ & $-.019(.02)$ & $-.004(.08)$ & $-.019(.02)$ \\
\hline Observed $^{\mathrm{a}}$ & $.196(.08)^{* *}$ & $-.108(.05)^{*}$ & $.199(.08)$ & $-.088(.05)$ & $.193(.07)^{* *}$ & $-.125(.05)^{* *}$ & $.208(.07)^{* *}$ & $-.109(.05)^{* *}$ \\
\hline \multicolumn{9}{|c|}{ Gene $\times$ Intervention effect on externalizing behavior: } \\
\hline Reported $^{\mathrm{a}}$ & $-.022(.15)$ & $-.183(.07)^{* *}$ & $.046(.15)$ & $-.149(.08)^{*}$ & $-.077(.15)$ & $-.184(.07)^{* *}$ & $-.077(.15)$ & $-.168(.07)^{* *}$ \\
\hline Observed $^{\mathrm{a}}$ & $.005(.15)$ & $-.003(.10)$ & $.078(.16)$ & $-.032(.11)$ & $-.066(.14)$ & $.064(.10)$ & $.001(.15)$ & $.037(.10)$ \\
\hline \multicolumn{9}{|c|}{ Intervention effect on positive parenting: } \\
\hline Reported ${ }^{\mathrm{b}}$ & $.131(.09)$ & $.141(.04)^{* *}$ & $.113(.09)$ & $.191(.05)^{* * *}$ & $.097(.08)$ & $.085(.04)^{*}$ & $.101(.08)$ & $.154(.04)^{* * *}$ \\
\hline \multicolumn{9}{|c|}{ Slope positive parenting by genes on externalizing behavior: } \\
\hline Reported ${ }^{\mathrm{a}}$ & & $-.881(.43)^{*}$ & & $-.657(.32)^{*}$ & & $-1.682(.82)^{*}$ & & $-.814(.07)^{\dagger}$ \\
\hline
\end{tabular}

${ }^{\mathrm{a}}$ Model fitted the data good. ${ }^{\mathrm{b}}$ Model fitted the data mediocre.

${ }^{\dagger} p<.08 .{ }^{*} p<.05 .{ }^{* *} p<.01 .{ }^{* * *} p<.001$.

displayed in Table 4 indicate boys with high polygenic scores whose parents increased a lot in the intervention condition showed the greatest decline in parent-reported externalizing behavior in all analyses (though in one case the effect was not significant, $p<.08)$. These results underscore the robustness of results in the primary analyses chronicling the genetic moderation of intervention efficacy.

\section{Discussion}

The purpose of this study was to evaluate (a) whether some children prove more susceptible than others to the beneficial effects of the IY parent training program due to their greater genetic plasticity, measured by means of a polygenic dopaminergic index, and (b) whether this would prove especially 
the case when parents increased their positive parenting behavior substantially in response to the IY program. In pursing these aims, we sought to extend recent observational and intervention research, which has focused mostly on single candidate genes as moderators of environmental effects (Belsky \& Van IJzendoorn, 2015; Van IJzendoorn \& Bakermans-Kranenburg, 2015). We created a composite polygenic index of select dopaminergic genes in order to focus on a specific functional system that might moderate the anticipated effect of the IY program (Nikolova et al., 2011).

Results revealed that boys, but not girls, carrying many putative plasticity alleles decreased significantly in parent-reported, but not observed, externalizing behavior as a result of their parents' involvement in the IY program. Such IY-treatmentinduced change was not evident in boys in the experimental group carrying few dopaminergic plasticity alleles - or boys assigned to the control group, irrespective of the latter's polygenic plasticity score. These results are consistent with the meta-analytic findings of Van IJzendoorn and Bakermans-Kranenburg (2015) indicating that effects of diverse experimental manipulations and interventions are substantially stronger in the case of carriers of putative plasticity alleles than those presumed, for genetic reasons, to be less susceptible to environmental influences. Upon first consideration, the findings for boys appear consistent with the differential susceptibility theory (Belsky \& Pluess, 2009, 2013; Belsky et al., 2007; Boyce \& Ellis, 2005). The fact, however, that children assigned to the control group who had many plasticity alleles did not evince the greatest increase (or least decrease) in problems over time means that the forworse pattern of change did not materialize, only the for-better pattern.

Especially notable with respect to the $G \times I$ findings is that the genetically moderated intervention effect (on boys' parent-reported externalizing behavior) proved most pronounced when positive parenting behavior improved the most in response to the IY program. This seems to validate the claim that parent-training effects, like IY, on children's problem behavior are indirect and due to effects on positive parenting behavior (see also Klein Velderman, Bakermans-Kranenburg, Juffer, \& Van IJzendoorn, 2006). Such results raise questions about why some parents changed more than others - in a positive way-in response to the intervention. Quite conceivably it could have something to do with their own genetic makeup and therefore their dopaminergic plasticity. Unfortunately, this critical issue could not be addressed herein because genetic data on parents were not available (see Chhangur et al., 2015).

It is also notable that evidence of genetic moderation of intervention efficacy only emerged in child behavior reported by parents and not in case of observed externalizing behavior. This is consistent with the overall intervention effect for this sample (see Weeland, Chhangur et al., 2016). It seems plausible that the null $G \times I$ findings reported here for observed behavior could be due to the limited sampling period (i.e., $20 \mathrm{~min}$ ) and highly structured observation context. After all, parental reports reflect, presumably, extensive opportunity to observe child behavior across days, weeks, and months diverse situations.

Although the overall effects of the IY parent program (on boys and girls together) were more pronounced at the immediate posttest relative to the delayed follow-up (see Weeland, Chhangur et al., 2016), inspection of Figures 1 and 2 makes clear that, in the case of the more genetically susceptible boys, treatment effects were not especially evident immediately after the intervention but became so by about 4 months later. This observation suggests that it may take time, in the case of more genetically susceptible boys, for increases in positive parenting induced by the IY intervention to become consolidated and thus influence child behavior. Parenting interventions are designed to change the well established, coercive, and repetitive cycle of aversive parent-child interactions that induces and maintains antisocial behavior (coercive interaction, Patterson, 1982). Thus, it may take a while before increases in parenting-based reinforcement processes become established as a result of the IY program, thereby downregulating externalizing behavior.

Although the boys scoring lower on the polygenic index in the experimental group changed less than those with higher polygenic scores, the question arises whether this would have proven to be the case had the intervention lasted longer. Had more time been allowed for parents to improve their parenting, via more intervention sessions and/or as a result of a later occurring follow-up evaluation, it is possible that the intervention children with fewer plasticity alleles could have caught up with those who responded more quickly to the IY intervention. Also, a very different intervention - or even one administered at an earlier agemight have proven more effective with children with fewer plasticity alleles. Thus, even if we get to the point where we could confidently conclude that 
a particular program-like IY-does not work equally well for all, this would not lead to the conclusion that the unaffected children are entirely nonsusceptible to intervention effects but rather that different children may benefit from different approaches (e.g., Chorpita \& Daleiden, 2009).

It remains unclear why the hypothesized $G \times I$ effects emerged only in the case of boys. Importantly, this was not a statistical artifact of there being greater variance in boys' than girls' externalizing behavior. In fact, the overall main effect of the intervention was similar in both subsamples in case of reported externalizing behavior. Nevertheless, we are not the first to document polygenic moderation of an environmental effect that is restricted to boys. Belsky and Beaver (2011) observed the same when investigating effects of parenting on adolescent self-regulation in their nonexperimental research. Such results led them to speculate that girls may be more easily socialized, which could account for why girls carrying few putative plasticity alleles proved as subject to the parenting effects as those carrying many. It will take additional research to determine whether the Belsky and Beaver (2011) proposal indeed explains the variation in $\mathrm{G} \times \mathrm{I}$ findings across boys and girls chronicled herein. Further work is also called for to gain insight into the processes that could explain how the individual genes included in our polygenic index influence dopaminergic functioning in the brain and, thus, make some boys seemingly more susceptible to the beneficial effects of IY than others.

In addition to raising intriguing issues for future research, the current inquiry had multiple strengths. Most notably, it involved an experimental research design and focused on multiple rather than single candidate genes known to play a role in the functioning of dopaminergic neurotransmitter system. Genes selected were based on prior differential-susceptibility-related $G \times E$ and $G \times I$ findings. These strengths do not obviate limitations that must be acknowledged. Perhaps the most important, which applies to almost all RCTs, is that the generalization of results might be limited to families willing to be randomized, with equal chance of being assigned to an experimental and control group. Although some of the families that did not enroll may have been put off by the demand of attending 14 weekly sessions lasting $2 \mathrm{hr}$, others may have not been willing to take the chance of receiving no intervention service. Not to be overlooked is the relatively modest sample size. Even though an experimental design increases power relative to an observational study
(Bakermans-Kranenburg \& Van IJzendoorn, 2015), especially when testing a moderated intervention effect, it is certainly possible that a larger sample might have revealed significant intervention effects even in girls or boys carrying fewer putative plasticity alleles.

\section{References}

Bakermans-Kranenburg, M. J., \& Van IJzendoorn, M. H. (2011). Differential susceptibility to rearing environment depending on dopamine-related genes: New evidence and a meta-analysis. Development and Psychopathology, 23, 39-52. doi:10.1017/S0954579410000635

Bakermans-Kranenburg, M. J., \& Van IJzendoorn, M. H. (2015). The hidden efficacy of interventions: Gene $\times$ Environment experiments from a differential susceptibility perspective. Annual Review of Psychology, 66, 381-409. doi:10.1146/annurev-psych-010814-015407

Bakermans-Kranenburg, M. J., Van IJzendoorn, M. H., Pijlman, F. T. A., Mesman, J., \& Juffer, F. (2008). Experimental evidence for differential susceptibility: Dopamine D4 receptor polymorphism (DRD4 VNTR) moderates intervention effects on toddlers' externalizing behavior in a randomized controlled trial. Developmental Psychology, 44, 293-300. doi:10.1037/0012-1649. 44.1.293

Beauchaine, T. P., Webster-Stratton, C., \& Reid, M. J. (2005). Mediators, moderators, and predictors of 1-year outcomes among children treated for early-onset conduct problems: A latent growth curve analysis. Journal of Consulting and Clinical Psychology, 73, 371-388. doi:10.1037/0022-006X.73.3.371

Belsky, J., Bakermans-Kranenburg, M. J., \& Van IJzendoorn, M. H. (2007). For better or worse: Differential susceptibility to environmental influences. Current Directions in Psychological Science, 16, 300-304. doi:10.1111/j.1467-8721.2007.00525.x

Belsky, J., \& Beaver, K. M. (2011). Cumulative-genetic plasticity, parenting and adolescent self-regulation. Journal of Child Psychology and Psychiatry, 52, 619-626. doi:10.1111/j.1469-7610.2010.02327.x

Belsky, J., \& Pluess, M. (2009). Beyond diathesis stress: Differential susceptibility to environmental influences. Psychological Bulletin, 135, 885-908. doi:10.1037/ a0017376

Belsky, J., \& Pluess, M. (2013). Beyond risk, resilience, and dysregulation: Phenotypic plasticity and human development. Development and Psychopathology, 25, 1243-1261. doi:10.1017/S095457941300059X

Belsky, J., \& Van IJzendoorn, M. H. (2015). What works for whom? Genetic moderation of intervention efficacy. Development and Psychopathology, 27, 1-6. doi:10.1017/ S0954579414001254

Blum, K., Sheridan, P. J., Wood, R. C., Braverman, E. R., Chen, T. J., Cull, J. G., \& Comings, D. E. (1996). The D2 dopamine receptor gene as a determinant of reward 
deficiency syndrome. Journal of the Royal Society of Medicine, 89, 396-400. doi:10.1177/014107689608900711

Boyce, W. T., \& Ellis, B. J. (2005). Biological sensitivity to context: I. An evolutionary-developmental theory of the origins and functions of stress reactivity. Development and Psychopathology, 17, 271-301. doi:10.1017/ S0954579405050145

Brody, G. H., Yu, T., \& Beach, S. R. H. (2015). A differential susceptibility analysis reveals the "who and how" about adolescents' responses to preventive interventions: Tests of first- and second-generation Gene $\times$ Intervention hypotheses. Development and Psychopathology, 27, 37-49. doi:10.1017/S095457941400128X

Byrd, A. L., \& Manuck, S. B. (2014). MAOA, childhood maltreatment, and antisocial behavior: Meta-analysis of a gene-environment interaction. Biological Psychiatry, 75, 9-17. doi:10.1016/j.biopsy.2013.05.004

Campbell, S. B., Spieker, S., Burchinal, M., Poe, M. D., Belsky, J., Booth-LaForce, C., . . . Weinraub, M. (2006). Trajectories of aggression from toddlerhood to age 9 predict academic and social functioning through age 12. Journal of Child Psychology and Psychiatry, 47, 791800. doi:10.1111/j.1469-7610.2006.01636.x

Cheong, J., MacKinnon, D. P., \& Khoo, S. T. (2003). Investigation of mediational processes using parallel process latent growth curve modeling. Structural Equation Modelling, 10, 238-262. doi:10.1207/S15328007SEM1002_5

Chhangur, R. R., Weeland, J., Matthys, W., \& Overbeek, G. (2015). Gene by environment research to prevent externalizing problem behavior: Ethical questions raised from a public healthcare perspective. Public Health Ethics, 8, 295-304. doi:10.1093/phe/phv024

Chhangur, R. R., Weeland, J., Overbeek, G., Matthys, W., \& Orobio de Castro, B. (2012). ORCHIDS: An observational randomized controlled trial on childhood differential susceptibility. BMC Public Health, 12, 917-923. doi:10.1186/1471-2458-12-917

Chorpita, B. F., \& Daleiden, E. L. (2009). Mapping evidence-based treatments for children and adolescents: Application of the distillation and matching model to 615 treatments from 322 randomized trials. Journal of Consulting and Clinical Psychology, 77, 566-579. doi:10.1037/a0014565

Dishion, T. J., Connell, A., Weaver, C., Shaw, D., Gardner, F., \& Wilson, M. (2009). The family check-up with high-risk indigent families: Preventing problem behavior by increasing parents' positive behavior support in early childhood. Child Development, 27, 417-428. doi:10.1055/s-0029-1237430.Imprinting

Duncan, L. E., \& Keller, M. C. (2011). A critical review of the first 10 years of candidate gene-by-environment interaction research in psychiatry. Perspectives, 168, 1041-1049. doi:10.1176/appi.ajp.2011.11020191

Ellis, B. J., Boyce, W. T., Belsky, J., Bakermans-Kranenburg, M. J., \& Van IJzendoorn, M. H. (2011). Differential susceptibility to the environment: An evolutionary-neurodevelopmental theory. Development and Psychopathology, 23, 7-28. doi:10.1017/S0954579410000611
Eyberg, S. M., \& Pincus, D. (1999). Eyberg Child Behavior Inventory and Sutter-Eyberg Student Behavior InventoryRevised: Professional manual. Odessa, FL: Psychological Assessment Resources.

Foley, D. L., Eaves, L. J., Wormley, B., Silberg, J. L., Maes, H. H., Kuhn, J., \& Riley, B. (2004). Childhood Adversity, Monoamine Oxidase A Genotype, and Risk for Conduct Disorder. Archives of General Psychiatry, 61, 738-744.

Forehand, R., Lafko, N., Parent, J., \& Burt, K. B. (2014). Is parenting the mediator of change in behavioral parent training for externalizing problems of youth? Clinical Psychology Review, 34, 608-619. doi:10.1016/ j.cpr.2014.10.001

Gardner, F., Hutchings, J., Bywater, T., \& Whitaker, C. (2010). Who benefits and how does it work? Moderators and mediators of outcome in an effectiveness trial of a parenting intervention. Journal of Clinical Child $\mathcal{E}$ Adolescent Psychology, 39, 568-580. doi:10.1080/ 15374416.2010.486315

Gardner, F., Shaw, D. S., Dishion, T. J., Burton, J., \& Supplee, L. (2007). Randomized prevention trial for early conduct problems: Effects on proactive parenting and links to toddler disruptive behavior. Journal of Family Psychology, 21, 398-406. doi:10.1037/0893-3200.21.3.398

Gershoff, E. T. (2002). Corporal punishment by parents and associated child behaviors and experiences: A meta-analytic and theoretical review. Psychological Bulletin, 128, 539-579. doi:10.1037/0033-2909.128.4.539

Hu, L. T., \& Bentler, P. M. (1999). Cutoff criteria for fit indexes in covariance structure analysis: Conventional criteria versus new alternatives. Structural equation modeling: a multidisciplinary journal, 6, 1-55.

Jones, K., Daley, D., Hutchings, J., Bywater, T., \& Eames, C. (2008). Efficacy of the incredible years programme as an early intervention for children with conduct problems and ADHD: Long-term follow-up. Child: Care, Health and Development, 34, 380-390. doi:10.1111/j.13652214.2008.00817.x

Kegel, C. A. T., Bus, A. G., \& van IJzendoorn, M. H. (2011). Differential susceptibility in early literacy instruction through computer games: The role of the dopamine D4 receptor gene (DRD4). Mind Brain and Education, 5, 71-78. doi:10.1111/j.1751-228X.2011.01112.x

Kim-Cohen, J., Caspi, A., Taylor, A., Williams, B., Newcombe, R., Craig, I. W., \& Moffitt, T. E. (2006). MAOA, maltreatment, and gene-environment interaction predicting children's mental health: New evidence and a meta-analysis. Molecular Psychiatry, 11, 903-913. doi:10.1038/sj.mp.4001851

Klein Velderman, M., Bakermans-Kranenburg, M. J., Juffer, F., \& Van IJzendoorn, M. H. (2006). Effects of attachment-based interventions on maternal sensitivity and infant attachment: Differential susceptibility of highly reactive infants. Journal of Family Psychology, 20, 266-274. doi:10.1037/0893-3200.20.2.266

Laucht, M., Skowronek, M. H., Becker, K., Schmidt, M. H., Esser, G., Schulze, T. G., \& Rietschel, M. (2007). 
Interacting effects of the dopamine transporter gene and psychosocial adversity on attention-deficit/hyperactivity disorder symptoms among 15-year-olds from a high-risk community sample. Archives of General Psychiatry, 64, 585-590. doi:10.1016/S0084-3970(08)79273-9

Matthys, W., Vanderschuren, L. J. M. J., \& Schutter, D. J. L. G. (2013). The neurobiology of oppositional defiant disorder and conduct disorder: Altered functioning in three mental domains. Development and Psychopathology, 25, 193-207. doi:10.1017/S0954579412000272

McCart, M. R., Priester, P. E., Davies, W. H., \& Azen, R. (2006). Differential effectiveness of behavioral parenttraining and cognitive-behavioral therapy for antisocial youth: A meta-analysis. Journal of Abnormal Child Psychology, 34, 527-543. doi:10.1007/s10802-006-9031-1

Menting, A. T. A., Orobio de Castro, B., \& Matthys, W. (2013). Effectiveness of the incredible years parent training to modify disruptive and prosocial child behavior: A meta-analytic review. Clinical Psychology Review, 33, 901-913. doi:10.1016/j.cpr.2013.07.006

Mesman, J., Bongers, I. L., \& Koot, H. M. (2001). Preschool developmental pathways to preadolescent internalizing and externalizing problems. Journal of Child Psychology and Psychiatry, 42, 679-689. doi:10.1111/ 1469-7610.00763

Miner, J. L., \& Clarke-Stewart, K. A. (2008). Trajectories of externalizing behavior from age 2 to age 9: Relations with gender, temperament, ethnicity, parenting, and rater. Developmental Psychology, 44, 771-786. doi:10.1037/0012-1649.44.3.771

Moore, S. R., \& Depue, R. A. (2016). Neurobehavioral foundation of environmental reactivity. Psychological Bulletin, 142, 107-164. doi:10.1037/bul0000028

Muthén, L. K., \& Muthén, B. O. (1998). Mplus user's guide 5. Los Angeles, CA: Author.

Nikolova, Y. S., Ferrell, R. E., Manuck, S. B., \& Hariri, A. R. (2011). Multilocus genetic profile for dopamine signaling predicts ventral striatum reactivity. Neuropsychopharmacology, 36, 1940-1947. doi:10.1038/npp.2011.82

Patterson, G. R. (1982). Coercive family process. Eugene, OR: Castalia.

Pettit, G. S., \& Bates, J. E. (1989). Family interaction patterns and children's behavior problems from infancy to 4 years. Developmental Psychology, 25, 413-420. doi:10.1037/0012-1649.25.3.413

Plak, R. D., Kegel, C. A. T., \& Bus, A. G. (2015). Genetic differential susceptibility in literacy-delayed children: A randomized controlled trial on emergent literacy in kindergarten. Development and Psychopathology, 27, 69-79. doi:10.1017/S0954579414001308

Pluess, M., \& Belsky, J. (2013). Vantage sensitivity: Individual differences in response to positive experiences. Psychological Bulletin, 139, 901-916. doi:10.1037/a0030196

Posthumus, J. A., Raaijmakers, M. A. J., Maassen, G. H., Van Engeland, H., \& Matthys, W. (2012). Sustained effects of incredible years as a preventive intervention in preschool children with conduct problems. Journal of
Abnormal Child Psychology, 40, 487-500. doi:10.1007/ s10802-011-9580-9

Propper, C., Willoughby, M., Halpern, C. T., Carbone, M. A., \& Cox, M. (2007). Parenting quality, DRD4, and the prediction of externalizing and internalizing behaviors in early childhood. Developmental Psychobiology, 49, 619632. doi:10.1002/dev.20249

Raaijmakers, M. A., Posthumus, J. A., Van Hout, B. A., Van Engeland, H., \& Matthys, W. (2011). Cross-sectional study into the costs and impact on family functioning of 4-year-old children with aggressive behavior. Prevention Science, 12, 192-200. doi:10.1007/s11121-0110204-y

Robinson, E. A., \& Eyberg, S. M. (1981). The dyadic parent-child interaction coding system: Standardization and validation. Journal of Consulting and Clinical Psychology, 49, 245-250. doi:10.1037/0022-006X.49.2.245

Scott, S., Knapp, M., Henderson, J., \& Maughan, B. (2001). Financial cost of social exclusion: Follow up study of antisocial children into adulthood. British Medical Journal, 323, 191-194. doi:10.1136/bmj.323. 7306.191

Scott, S., Spender, Q., Doolan, M., Jacobs, B., \& Aspland, H. (2001). Multicentre controlled trial of parenting groups for childhood antisocial behaviour in clinical practice. British Medical Journal, 323, 194-198.

Shaw, D. S., Keenan, K., \& Vondra, J. I. (1994). Developmental precursors of externalizing behavior: Ages 1 to 3. Developmental Psychology, 30, 355-364. doi:10.1037/ 0012-1649.30.3.355

Van IJzendoorn, M. H., \& Bakermans-Kranenburg, M. J. (2015). Genetic differential susceptibility on trial: Metaanalytic support from randomized controlled experiments. Development and Psychopathology, 27, 151-162. doi:10.1017/S0954579414001369

Vaughn, M. G., Salas-wright, C. P., Delisi, M., \& Maynard, B. R. (2013). Violence and externalizing behavior among youth in the United States: Is there a severe 5\%? Youth Violence and Juvenile Justice, 12, 3-21. doi:10.1177/1541204013478973

Webster-Stratton, C. (1989). Dyadic Parent-Child Interaction Coding System-Revised. Unpublished manuscript.

Webster-Stratton, C. (2001a). Parenting practices interview. Unpublished assessment instrument. Retrieved from http://www.son.washington.edu/centers/parentingclinic/forms.asp

Webster-Stratton, C. (2001b). The incredible years: Parents and children videotape series: A parenting course (BASIC). Seattle, WA: Incredible Years.

Webster-Stratton, C., \& Hammond, M. (1997). Treating children with early-onset conduct problems: A comparison of child and parent training interventions. Journal of Consulting and Clinical Psychology, 65, 93-109. doi:10.1037/0022-006X.65.1.93

Weeland, J., Chhangur, R. R., Van der Giessen, D., Matthys, W., Orobio de Castro, B., \& Overbeek, G. (in press). Intervention effectiveness of the incredible years 
parent training: New insight into sociodemographic and intervention-based moderators. Behavior Therapy.

Zuckerman, M. (1999). Vulnerability to psychopathology: A biosocial model. Washington, DC: American Psychological Association.

\section{Supporting Information}

Additional supporting information may be found in the online version of this article at the publisher's website:

Figure S1. Development of Observed Externalizing Behavior in Boys (as Indicated by Scores on the Dyadic Parent-Child Interaction Coding System [DPICS] Child Negative Behavior Scale) Across Pretest, Posttest, and Follow-Up for Control and
Intervention Groups With 0-2 Putative Polygenetic Plasticity Alleles or 3-5 Such Alleles

Figure S2. Development of Parent-Reported Externalizing Behavior in Case of Girls (as Indicated by Scores on the Eyberg Child Behavior Inventory [ECBI] Intensity Score Scale) Across Pretest, Posttest, and Follow-Up for Control and Intervention Groups With 0-2 Putative Polygenetic Plasticity Alleles or 3-5 Such Alleles

Figure S3. Development of Observed Externalizing Behavior in Girls (as Indicated by Scores on the Dyadic Parent-Child Interaction Coding System [DPICS] Child Negative Behavior Scale) Across Pretest, Posttest, and Follow-Up for Control and Intervention Groups With 0-2 Putative Polygenetic Plasticity Alleles or 3-5 Such Alleles 